Don as an excellent teacher, advisor, and researcher, I think the most important for me was the fact that he treated me as a colleague and collaborator as soon as I became his graduate student.

"My stay at lowa was very short. Even I was not prepared for graduation so soon. Yes, I did turn down my first job offer from Ed Shelley at Lockheed. It was a difficult decision, but I saw an important opportunity to work with Michelle Thomsen at Los Alamos and essentially extend my "graduate studies" another 2 years. I had heard that Michelle was an excellent researcher; she made a significant effort to get me a postdoc at Los Alamos; and she can be very, very persuasive.

"Los Alamos was a important transition for me. One example should suffice. The strongest language Don ever used concerning a particular aspect of some of my thesis work that he felt was probably not correct was when he told me 'Stephen, I'm fairly negative about this.' Contrast that with my first encounter with Jack Gosling at Los Alamos. After my introductory Los Alamos seminar on my thesis work, Jack stood up and asked 'Do you really believe all this?'
Without waiting for a response, he proceeded to tell me why he did not. Despite this introduction, I came to respect Michelle and Jack as two of the finest people I've ever worked with. Most important, they gave me a recipe for successful scientific collaboration. Like most things, this was stated bluntly and simply by Jack as 'get yourself in a small group of scientists that brings diverse talents to a problem that they all want to 'solve.'

"I have tried to follow this recipe throughout my career. I can recall several examples where this has worked very well, starting with my thesis work. One of the more recent examples was the work that Brian Anderson, Richard Denton, Peter Gary, and I did on the Earth's magnetosheath. That work grew out of a presentation by Brian at one of the many enjoyable and highly successful AMPTE (Active Magnetospheric Particle Tracer Explorers) joint science team meetings.

"At Lockheed-Martin, I've found that this type of successful collaboration is fostered by Ed Shelley and the other members of the space sciences group. Ed has been my boss and, more important, my colleague since I came to the space sciences laboratory. In the nearly 10 years that I've worked with him, he has always encouraged me to pursue a variety of topics, both internal and external to our group. He is always open to new ideas and can always provide lucid comments on just about any subject from ion mass spectrometers to how to open a bottle of wine with your shoe.

"Finally, l'd like to point out that the work my colleagues and I have done over these years was done largely using what we in the business like to call mature spacecraft data. To provide an example of what I mean by mature data, Ed Shelley began designing and building the ISEE ion mass spectrometer about the time I was entering high school. The spacecraft was launched, and the first data from that spectrometer were returned to Earth about the time I began my undergraduate work. Today, over 17 years later, these initial data that we continue to analyze represent some of the best and in many cases the only observations of their kind.

"In conclusion, I hope I have demonstrated that my success is really a reflection on those people who have helped me in my career."-Stephen A. Fuselier, Lockheed Research Laboratory, Palo Alto, Calif.

\title{
Lunine Receives Macelwane Medal
}

\section{PAGES 63,67}

The 1995 James B. Macelwane Medal, given by AGU for significant contributions to the geophysical sciences by a young scientist of outstanding ability, was presented to Jonathan Lunine at the AGU Fall Meeting Honor Ceremony on December 13, 1995, in San Francisco. The award citation and Lunine's response are given here.

\section{Citation}

"Jonathan Lunine is a remarkably talented and accomplished scientist, best known in the planetary community for his work on the nature of icy bodies. It is rather startling to think that he could still win a young scientist award, because his published contributions now span almost 15 years, and his impact and role is very much one of an authority figure. As if the planetary work were not sufficient accomplishment, Jon has also contributed to our understanding of brown dwarfs, objects whose existence has been long in dispute, but for which the evidence is now (at long last) very strong.

"Jon grew up in New York City and attended the University of Rochester, where the influences included Hugh van Horn, a prominent astrophysicist. He came to Cal- tech as a graduate student in 1980 , the same time that I came to Caltech as a faculty member, and Jon was my first Ph.D. student. In retrospect, I did not realize how remarkable he was, since I had never had the opportunity to work closely with a typical student and thereby know the difference. One of the striking things about Jon Lunine was (and is) his capacity for getting things done, and in his relatively short 4 years at Caltech, he worked on many projects with several people. His most notable accomplishment in that period was a synthesis of theory and observational constraints for the volatile reservoirs of Titan, the large satellite of Saturn and the only satellite in the solar system with a thick atmosphere. This work led to the prediction of a hydrocarbon, principally ethane ocean, a concept that evolved from a wild speculation to firmly based reasoning. Although radar data suggest that the simplest version of this idea is probably incorrect, the presence of a surficial or near-surface hydrocarbon reservoir seems inescapable, based on the arguments he developed. Jon's current major role in the Titan probe for the upcoming Cassini mission to Saturn will enable him to stay on top of this fascinating issue: Is there another body in our solar system with oceans? In his Caltech period, he also worked on the thermodynamics of ices, especially

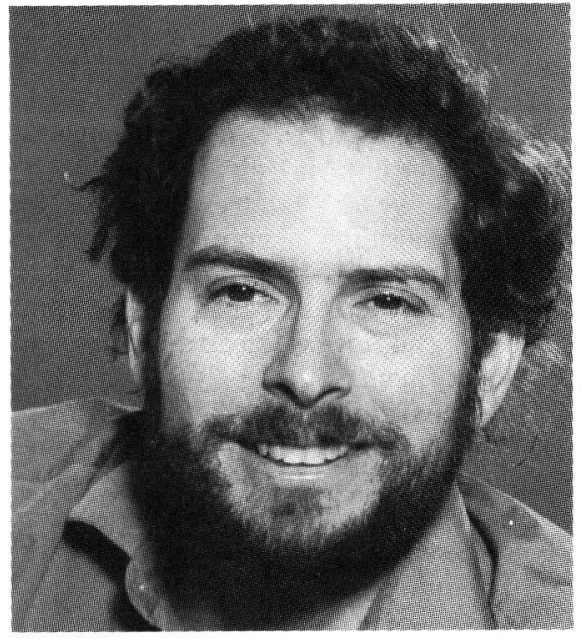

clathrates, an effort that formed the basis for much later work on icy bodies.

"After Caltech, Jon went to the University of Arizona, first as a postdoc, then as a professor rising through the ranks. In this period, extending up until the present, he played a major role in developing our current understanding of the atmosphere of Pluto, developed models for the nature of cometary ices and the composition of planetesimals in the early solar system, made the first (and necessarily simplified) calculations of the spectra of brown dwarfs, collaborated on models of the nature of moist convection in planetary atmospheres, and contributed to other topics too numerous to mention. Most of this work has been collaborative, and with many different collaborators, including his 
own students. In recent times, he has contributed much to the planning of future space missions through his leadership role in NASA advisory activities and his important role in Cassini.

"The distinguishing characteristic of Jon Lunine's science is the combination of $\mathrm{di}$ verse data with theoretical modeling that most directly addresses these data. I chose these words carefully: Much theoretical modeling is either focused on a specific data set (e.g., measurement of some atmospheric species) or divorced from data (i.e., difficult to test). Jon has a special ability to synthesize; an ability that is rare because it requires a very broad knowledge. Of course, it is exactly the skill that one needs to have a big impact in planetary science, and his approach has paid off well.

"Planetary science is a science undergoing change, partly because of the limits to resources needed to mount missions, but also because we are moving beyond the first flush ¿ exploration to more detailed study. Howzver, as we come to discover other planetary systems and l'm sure we will, Jonathan Lunine will be there and contributing to one of the most exciting scientific challenges I can imagine."-David J. Stevenson, Caltech, Pasadena, Calif.

\section{Response}

"Thank you, David .. . I am very pleased to accept a James B. Macelwane Medal from the American Geophysical Union. I first wish to say a few words about David Stevenson, who more than anyone else shaped my philosophy and approach toward science. The planetary science community in particular, and geophysics in general, are privileged to have David Stevenson in our midst. David's extraordinary dedication to science, his abundant creativity, and his steadfast adherence to the highest standards of intellectual rigor and honesty are evident to all who have interacted with him or studied his work. The many hours I spent in David's office discuss- ing scientific problems give new meaning to the pop-psychology term "quality time." Moreover, although David didn't mention this, I owe to him my now longstanding enjoyment of hiking and backpacking ... skills which were honed on a number of memorable and infamous "death marches" through various California mountains.

"After 4 years in the California Institute of Technology's extraordinary intellectual environment have come 11 wonderful years at Arizona's Lunar and Planetary Laboratory (LPL), in an atmosphere very different from Caltech's, but no less nurturing for doing science. Don Hunten, Bill Hubbard, Randy Jokipii, and John Lewis started as financial benefactors and became close senior colleagues, with whom doing science has always been enjoyable. I must express my gratitude to Gene Levy, now Dean of Science but for 10 years director of LPL, for fostering a remarkably collaborative institutional environment, and to Mike Drake, current LPL Director, for perpetuating this happy situation. Beyond the University of Arizona are a terrific group of colleagues, both contemporary and senior, whose enthusiasm for the stillyoung scientific discipline of planetology has been infectious. I particularly wish to mention in this regard Larry Soderblom, Torrence Johnson, and Dennis Matson.

"My wife, Cynthia, has been a wonderful companion on many adventures over a decade and, despite having no degree in science, has helped increase the signal-to-noise ratio in my presentations and papers. I owe my mother, Joan Bean, a huge thanks for sustaining the family in difficult times; my late father, Lewis, for encouraging my early interest in science; and my stepfather, Norman Jacobs, for showing me how a wild Australian does industrial-strength science. Finally, coming back full circle to my undergraduate days at the University of Rochester, I thank Hugh Van Horn for his warm advice, always well-considered, which helped steer me into planetary science, and Roger Phillips, Director of Lunar Planetary Institute in Houston when I interned there in 1980 , who told me I should work with Dave Stevenson and I should not rush through graduate school. I took half of Roger's advice.

"In his citation David referred to the search for other planetary systems, and I wish to comment on that subject. It is now passè to claim that we stand on the verge of a revolution in discovering new solar systems, because we have thought that we have stood on that verge a number of times already over the past couple of decades. Nonetheless, I would assert that the goal of discovering and characterizing terrestrial-type planets around other stars is in reach within the career lifetimes of many people in this room. Over the last several years, novel concepts in adaptive optics, interferometry, and other techniques have been proposed such that one can plausibly lay out a way to do this. Whether terrestrial-type planets are out there to be discovered, as opposed to misfits and oddballs such as the bizarre object orbiting 51 Pegasi, remains to be determined. But it is clear that the search itself addresses one of humanity's greatest questions, namely, whether Earth bears the only sentient entities in the cosmos.

"The search for other planetary systems would be at best unsatisfying (and, in truth, extremely difficult) without an understanding of the origin and evolution of our own solar system and its numerous, remarkably diverse, planets and natural satellites. The solar system remains fertile ground for exploration. Missions like Galileo, which successfully arrived at Jupiter last week, Cassini, to be launched to Saturn and Titan in 1997 . and Magellan, about which we heard much today, are essential if we are to remain capable of addressing the big questions in planetology. The scientific study of our own solar system and the search for others are two sides of an extraordinary intellectual adventure in which I feel very fortunate to participate.

"Thank you."---Jonathan I. Lunine, University of Arizona, Lunar and Planetary Laboratory, Tucson

\section{In Brief}

\section{PAGE 62}

Deadly quake More than 250 people died and at least 15,000 were injured when an earthquake struck the Lijiang and Zhongdian regions of southwestern China at 7:14 p.m. local time on February 3. Over 300,000 people were left homeless, while temperatures hovered near the freezing point, as more than 186,000 homes were severely damaged--roughly $80 \%$ of the local total. Entire villages in the Yunnan Province were obliterated, with the worst damage coming in Dayan township and in the rural areas of White Sand and Gold Mountain. The death toll was expected to rise to at least 300 , officials of the Chinese Red Cross estimated.

The worst earthquake to hit China in eight years was centered at $27.3^{\circ} \mathrm{N}, 100.4^{\circ} \mathrm{W}$, about $150 \mathrm{~km}$ WNW of Dukou, and at a depth of 33 $\mathrm{km}$, according to researchers at the National Earthquake Information Center of the U.S. Geological Survey (USGS). The earthquake had a moment magnitude of $6.7\left(\mathrm{M}_{\mathrm{w}}\right)$, according to the USGS, although Chinese officials were reporting the quake as $7.0 \mathrm{M}_{\mathrm{w}}$. As of February 6, a total of 312 aftershocks had been recorded, with a half-dozen aftershocks greater than $5.0 \mathrm{M}_{\mathrm{w}}$ and 18 greater than 4.0 $\mathrm{M}_{\mathrm{w}}$. (Some information for this report was provided by Reuters and the Associated Press.)

A tangled web Add another strand to the web of life. The concentration of oxygen in the Earth's oceans and atmosphere appears to be indirectly linked in a feedback system to the productivity of marine organisms, according to Earth scientists Phillippe Van Cappellen of Georgia Tech and Ellery Ingall of the University of Texas at Austin.

Studying ancient and modern sediment cores from the sea floor, the two researchers found that when the oceans are more fully oxygenated, they store more phosphorus; when the oxygen supply is depleted, the phosphorus concentration in sediments is reduced as well. "This is critical because the productivity of the oceans appears to be limited by how much phosphorus is available."

Some of that change in oxygen and phosphorus concentrations can be accounted for 